\title{
Article
}

\section{Investigations into the potential anticancer activity of Maximin H5}

Dennison, Sarah Rachel, Harris, Frederick and Phoenix, David A.

Available at http://clok.uclan.ac.uk/17217/

Dennison, Sarah Rachel ORCID: 0000-0003-4863-9607, Harris, Frederick and Phoenix, David A. (2017) Investigations into the potential anticancer activity of Maximin H5. Biochimie, 137 . pp. 29-34. ISSN 0300-9084

It is advisable to refer to the publisher's version if you intend to cite from the work. http://dx.doi.org/10.1016/j.biochi.2017.02.013

For more information about UCLan's research in this area go to http://www.uclan.ac.uk/researchgroups/ and search for < name of research Group>.

For information about Research generally at UCLan please go to http://www.uclan.ac.uk/research/

All outputs in CLoK are protected by Intellectual Property Rights law, including Copyright law. Copyright, IPR and Moral Rights for the works on this site are retained by the individual authors and/or other copyright owners. Terms and conditions for use of this material are defined in the policies page.

\section{CLoK}

Central Lancashire online Knowledge www.clok.uclan.ac.uk

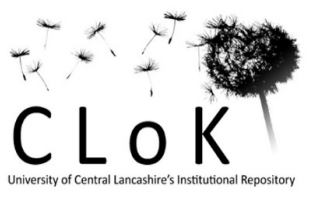




\title{
Maximin $\mathrm{H} 5$ is an anticancer peptide
}

\author{
Sarah R. Dennison ${ }^{1}$, Frederick Harris ${ }^{2}$ and David A. Phoenix ${ }^{3 *}$
}

${ }^{1}$ School of Pharmacy and Biomedical Sciences, University of Central Lancashire, Preston PR1 2HE, UK.

${ }^{2}$ School of Forensic and Investigative Science, University of Central Lancashire, Preston PR1 2HE, UK.

${ }^{3}$ School of Applied Science, London South Bank University, 103 Borough Road, London SE1 OAA, UK

Author for correspondence:

Prof D A Phoenix, Office of the Vice Chancellor, London South Bank University, 103 Borough Road, London SE1 0AA, UK.

Phone: +44 (0) 207815 6001, Fax: +44 (0) 207815 6099, E-mail: phoenixd@lsbu.ac.uk 


\section{Abstract}

Here we report the first major example of anionic amphibian host defence peptides (HDPs) with anticancer activity. Maximin H5 is a C-terminally amidated, anionic host defence peptide (MH5N) from toads of the Bombina genus, which was shown to possess activity against the glioma cell line, T98G $\left(\mathrm{EC}_{50}=125 \mu \mathrm{M}\right)$. The peptide adopted high levels of $\alpha$ helical structure (57.3\%) in the presence of model cancer membranes (DMPC:DMPS in a molar ratio of 10:1). MH5N also showed a strong ability to penetrate these model membranes $\left(\Pi=10.5 \mathrm{mN} \mathrm{m}^{-1}\right)$, which correlated with levels of DMPS $\left(\mathrm{R}^{2}>0.98\right)$. Taken with the high ability of the peptide to lyse these membranes (65.7\%), it is proposed that maximin H5 kills cancer cells via membranolytic mechanisms that are promoted by anionic lipid. It was also found that C-terminally deaminated maximin H5 (MH5C) exhibited lower levels of $\alpha$-helical structure in the presence of cancer membrane mimics (44.8\%) along with a reduced ability to penetrate these membranes $\left(\Pi=8.1 \mathrm{mN} \mathrm{m}^{-1}\right.$ ) and induce their lysis (56.6\%). These data suggested that the two terminal amide groups of native maximin $\mathrm{H} 5$ are required for its optimal membranolytic and anticancer activity. 
Dennison SR, Harris F and Phoenix DA (2017) Maximin H5 is an anticancer peptide, Biochimie accepted 27/02/2017. http://dx.doi.org/10.1016/j.biochi.2017.02.013

\title{
Highlights
}

- Maximin H5 (MH5N) is an anionic, $\alpha$-helical host defence peptide from amphibians.

- MH5N kills cancer cells via membranolytic mechanisms promoted by anionic lipid.

- C-terminal deamidation of MH5N reduces its $\alpha$-helicity and membranolytic activity.

\section{Key words}

anticancer activity, $\alpha$-helical peptide, host defence peptides, lipid monolayers, maximin H5, membranolytic,

\begin{abstract}
Abbreviations
dimyristoyl phosphatidylcholine, DMPC; dimyristoyl phosphatidylserine, DMPS; host defence peptides, HDPs; maximin H5, MH5N; C-terminally deamidated maximin H5, MH5C; phosphate buffered saline, PBS.
\end{abstract}


Dennison SR, Harris F and Phoenix DA (2017) Maximin H5 is an anticancer peptide, Biochimie accepted 27/02/2017. http://dx.doi.org/10.1016/j.biochi.2017.02.013

\subsection{Introduction}

Globally, cancer is a leading cause of death that is expected to grow in the coming years $[1,2]$ and a host of strategies have been adopted to generate novel anticancer compounds $[3,4]$, ranging from the design of nanoparticle drugs [5] to the development of naturally occurring plant molecules [6]. Another promising strategy for the development of novel anticancer compounds is centred on host defence peptides (HDPs), which are highly effective antibiotics of the innate immune system [7]. These peptides have been under investigation as therapeutically relevant antimicrobial agents for a number of years but it has become increasingly clear that many HDPs also exhibit potent anticancer activity [8-10]. This activity generally involves membrane interaction and employs relatively non-specific modes of action at multiple sites, which has led to the view that cancer cells have a low likelihood of developing resistance to HDPs, potentially giving these peptides a major advantage over many established anticancer compounds [7]. Indeed, the rapidly increasing interest in the potential of HDPs to act as medically relevant agents in the treatment of cancer is reflected by the fact that a database dedicated solely to the anticancer activity of these peptides has recently been launched, namely CancerPPD [11]. A number of HDPs have also entered clinical trials as potential anticancer agents [12], such as bovine lactoferrin, which was patented in this capacity [13] and was shown to reduce the risk of colon carcinogenesis in humans [14]. More recent examples include human LL-37 and a synthetic homologue of HDPs, LTX-315, which are both currently awaiting phase I / II clinical trials for the treatment of a variety of human cancers, including melanoma and lymphoma $[15,16]$.

Each of the peptides described above as in clinical trials is cationic, as is the vast majority of HDPs that has been reported to exhibit activity against cancer cells [7-9,12]. However, an increasing number of anionic HDPs are being reported $[17,18]$ and only a few of these peptides have been tested for anticancer activity, mainly those from plants $[19,20]$, such 
Dennison SR, Harris F and Phoenix DA (2017) Maximin H5 is an anticancer peptide, Biochimie accepted 27/02/2017. http://dx.doi.org/10.1016/j.biochi.2017.02.013

as Cn-AMP2 [21] and kalata B2 [22]. Accordingly, here we have investigated the anticancer potential of maximin H5, which is one of a number of anionic HDPs isolated from the skin secretions and brains of toads from the Bombina genus [23,24]. The peptide was found to have activity against the T98G glioma cell line via membranolytic mechanisms that were promoted by anionic lipid in the membranes of these cells and required the two terminal amide groups of the peptide for optimal anticancer activity. This would appear to be the first major report of anionic amphibian HDPs with anticancer activity.

\subsection{Materials and Methods}

\subsubsection{Reagents}

A synthetic homologue of maximin H5, MH5N (ILGPVLGLVSDTLDDVLGIL$\mathrm{CONH}_{2}$ ), and its C-terminally deamidated isoform, MH5C (ILGPVLGLVSDTLDDVLGIL$\mathrm{COOH}$ ), were manufactured by Pepceuticals (Leicestershire, UK) by solid state synthesis and purified by HPLC to purity greater than 95\%. The phospholipids: dimyristoyl phosphatidylserine (DMPS) and dimyristoyl phosphatidylcholine (DMPC) were supplied by Avanti Polar Lipids (Alabaster, Alabama) and were used without further purification. All other reagents were supplied by SIGMA (UK) and VWR (UK) unless otherwise stated.

\subsubsection{The ability of maximin H5 isoforms to kill cancer cells}

The non-cancerous human foetal glial cell line, SVGp12, and the human glioblastoma cell line, T98G, were obtained from the European collection of cell cultures 
Dennison SR, Harris F and Phoenix DA (2017) Maximin H5 is an anticancer peptide, Biochimie accepted 27/02/2017. http://dx.doi.org/10.1016/j.biochi.2017.02.013

(http://www.ecacc.org.uk). These cells were grown and then maintained in Minimum Essential Medium Eagle supplemented with 2.5\% (v/v) foetal bovine serum, 2 mM Lglutamine, $1 \mathrm{mM}$ sodium pyruvate and 1\% (v/v) non-essential amino acids (Lonza, UK). Each of these cell lines was maintained in a $37^{\circ} \mathrm{C}$ humidified incubator supplied with $5 \% \mathrm{CO}_{2}$, all as previously described [25]. To investigate the anticancer potential of maximin H5 isoforms, cell cultures were trypsinised and seeded in 96-well microtitre plates (Sarstedt, UK) such that wells contained a cell density of either 4500 SVGp12 cells / $200 \mu$ l or 4000 T98G cells / 200 $\mu \mathrm{l}$. The following day when the cells were circa 70\% confluent, MH5N and MH5C (final concentration varying between $10 \mu \mathrm{M}$ and $200 \mu \mathrm{M}$ ) were added to wells and the plates left to incubate for 72 hours, all as previously described [25]. After this period of incubation, the viability of these peptide-treated cells was determined using the CellTiter 96® AQueous One Solution Cell Proliferation Assay (Promega, UK; MTS assay [26]) according to manufacturer’s instructions. Essentially, $20 \mu \mathrm{l}$ of pre-warmed MTS reagent was added to wells under investigation and the plates incubated at $37^{\circ} \mathrm{C}$ in a humidified incubator supplied with $5 \% \mathrm{CO}_{2}$ for $60 \mathrm{~min}$. At the end of this time, the absorbance of each well was recorded at $490 \mathrm{~nm}$ using a Tecan GENios Pro ${ }^{\circledR}$ microplate reader and used to determine \% cell viability. As controls, these experiments were repeated in the absence of the peptide and, in all cases, experiments were performed in quadruplicate. Non-linear regression analysis was used to yield the concentration of peptides that inhibited $50 \%$ of cancer cell growth ( $\mathrm{IC}_{50}$ ) when compared to untreated controls.

\subsubsection{Secondary structural analysis of maximin H5 isoforms using circular dichroism}

Secondary structure analysis was performed using a J-815 spectropolarimeter (Jasco, UK) at $20{ }^{\circ} \mathrm{C}$ as previously described [27]. Samples were prepared by dissolving MH5N and MH5C 
Dennison SR, Harris F and Phoenix DA (2017) Maximin H5 is an anticancer peptide, Biochimie accepted 27/02/2017. http://dx.doi.org/10.1016/j.biochi.2017.02.013

in phosphate buffered saline (PBS) and 2, 2, 2-trifluoroethanol / phosphate buffered saline (TFE / PBS; $50 \% \mathrm{v} / \mathrm{v}$ ) to give a final peptide concentration of $60 \mu \mathrm{M}$ in each case. CD structural analysis was also performed with MH5N and MH5C in the presence of lipid. DMPC (19 mg $\mathrm{ml}^{-1}$ ), DMPS (19 $\mathrm{mg} \mathrm{ml}^{-1}$ ) and DMPC:DMPS (molar ratio 10:1) $\left(19 \mathrm{mg} \mathrm{ml}^{-1}\right.$ ) were dissolved in chloroform and dried under $\mathrm{N}_{2}$ gas before being vacuum-dried. The resulting lipid film was rehydrated using $1 \times \mathrm{PBS}(\mathrm{pH} 7.5)$ for an hour, or until the solution was no longer turbid, and then freeze-thawed 4 times, followed by extrusion 11 times with a $0.1 \mu \mathrm{m}$ polycarbonate filter using an Avanti Polar Lipids mini-extruder apparatus. Peptide / lipid samples were prepared by adding stock peptide solution to a measured volume of lipid suspension to obtain the desired peptide:lipid molar ratio (1:100) before being mixed thoroughly. Far UV (180 to 260nm) CD spectra were recorded using $0.5 \mathrm{~nm}$ intervals, a band width of $1 \mathrm{~nm}$, a scan speed $100 \mathrm{~nm} \mathrm{~min}{ }^{-1}$ and a $10 \mathrm{~mm}$ path-length cell. Four scans per sample were performed and averaged. For secondary structure estimation, CD spectra was deconvoluted using CDSSTR algorithm (protein reference set 3) on the DichroWeb server [28-30].

\subsubsection{Interaction of maximin H5 isoforms with lipid monolayers}

Lipid monolayers were formed by dropping chloroformic solutions of either DMPC, DMPS or DMPC:DMPS (molar ratio 10:1) onto a Tris buffer subphase (10 mM; pH 7.5) contained in an $80 \mathrm{ml}$ 601M Langmuir Teflon trough (Biolin Scientific/KSV NIMA, UK). Surface pressure (П) was measured using a Wilhelmy wire attached to a microbalance. After spreading, the solvent was allowed to evaporate off the subphase surface over 30 minutes, the barriers were closed at a rate of $5 \mathrm{~cm}^{2} \mathrm{~min}^{-1}$ until a starting pressure of $\Pi=30 \mathrm{mN} \mathrm{m}^{-1}$ was achieved, which is equivalent to that of the outer leaflet of a cell membrane [31]. Monolayers were allowed to equilibrate for a further 30 mins before MH5N and MH5C were injected into the subphase 
Dennison SR, Harris F and Phoenix DA (2017) Maximin H5 is an anticancer peptide, Biochimie accepted 27/02/2017. http://dx.doi.org/10.1016/j.biochi.2017.02.013

using an L-shaped Hamilton syringe without disruption of the monolayer. These experiments were repeated using monolayers formed from DMPC:DMPS at ratios of 100:1, 50:1, 20:1 and $10: 1$

\subsubsection{Interaction of maximin H5 isoforms with dye-filled lipid vesicles}

Either DMPC, DMPS or DMPC:DMPS (molar ratio 10:1) (7.5 mg) were dissolved in chloroform and dried under $\mathrm{N}_{2}$ gas before being vacuum-dried. The resulting lipid film was then hydrated with $1 \mathrm{ml}$ of HEPES (5.0 mM; pH 7.5) containing calcein (70 mM). The suspension was vortexed for 5 minutes and then sonicated for 30 mins after which, the solution underwent 3 cycles of freeze-thawing. Liposomes were extruded 11 times through a $0.1 \mu \mathrm{m}$ polycarbonate filter using an Avanti polar lipids min-extruder apparatus. Calcein entrapped vesicles were separated from free calcein by gel filtration using a Sephadex G75 column (SIGMA) which was rehydrated overnight in HEPES (20 mM; pH 7.5), $\mathrm{NaCl}$ (150 mM) and EDTA. (1.0 mM). The column was then eluted with HEPES (5 mM; pH 7.5). The calcein release assay was performed by combining $2 \mathrm{~mL}$ of HEPES (20 mM; pH 7.5), $\mathrm{NaCl}$ (150 mM) and EDTA $(1.0 \mathrm{mM})$ with $20 \mu \mathrm{l}$ of calcein vesicles. MH5N and MH5C (100 $\mu \mathrm{M})$ were incubated with these vesicles and the fluorescence intensities of released calcein measured using a FP-6500 spectrofluorometer (JASCO, Tokyo Japan), with an excitation wavelength of $490 \mathrm{~nm}$ and an emission wavelength of $520 \mathrm{~nm}$. Membrane lysis of $100 \%$ was taken as the fluorescence induced by Triton $\times 100(20 \mu \mathrm{l})$ when used to dissolve the vesicles. The percentage lysis achieved by MH5N and MH5C was then calculated relative to this standard.

\subsection{Results and discussion}

There is an urgent need for new drugs with novel mechanisms of action to treat cancers [1] and here we have investigated the anticancer ability of the amphibian peptide, maximin H5 
Dennison SR, Harris F and Phoenix DA (2017) Maximin H5 is an anticancer peptide, Biochimie accepted 27/02/2017. http://dx.doi.org/10.1016/j.biochi.2017.02.013

$[23,24]$. The native peptide, MH5N, was assayed for activity against the glioblastoma cell line, T98G and it was found that the peptide had a strong ability to reduce the viability of these cancer cells (70\%, Figure 1). Regression analysis yielded an $\mathrm{IC}_{50}$ value of $125 \mu \mathrm{M}$ for MH5N (Figure 1), which is comparable to that of other anionic HDPs [20] and also to the levels of the native peptide required for antibacterial activity [32]. In contrast, at the same concentrations, MH5N exhibited only a low ability to reduce the viability of the non-cancerous, human glial cell-line, SVGp12 (circa 10\%, Figure 1). In combination, these data show that native maximin H5 exhibits specificity for cancer cells and is able to strongly retard the growth of these cells in relation to non-transformed cells, which is consistent with the general lack of activity shown by the peptide against healthy eukaryotic cells, such as erythrocytes [24,32].

To investigate the anticancer effects of native maximin H5, CD spectroscopy was used to investigate the conformational behaviour of $\mathrm{MH} 5 \mathrm{~N}$, which showed that the peptide was predominantly unstructured in aqueous solution and exhibited no significant levels of $\alpha$-helical structure $(<10 \%$, Table 1$)$. Similar results have previously been reported for isoforms of maximin H5 [32,33], and it is well established that most $\alpha$-helix forming HDPs require an amphiphilic interface, such as that of membranes, to drive the adoption of this secondary structure [10,34]. Consistent with these observations MH5N exhibited high levels of $\alpha$-helical structure (68\%, Table 1) in the presence of TFE, which is a well known membrane micking agent [35] and in the presence of each of the lipid vesicle systems studied ( $\geq 45 \%$, Table 1 , Figure 2A). In particular, the peptide adopted 57.3\% $\alpha$-helicity in the presence of vesicles formed from DMPC:DMPS (molar ratio 10:1) (Table 1, Figure 2A), which is a lipid composition frequently used to mimic cancer cell membranes [21,36]. It is a distinguishing feature of cancer cell membranes that PS forms circa $10 \%$ of the total lipid in their outer leaflets, as opposed to the membranes of healthy eukaryotic cells where the lipid is primarily localised to the inner leaflet $[7,10]$. In combination, these data suggest that the ability of native 
Dennison SR, Harris F and Phoenix DA (2017) Maximin H5 is an anticancer peptide, Biochimie accepted 27/02/2017. http://dx.doi.org/10.1016/j.biochi.2017.02.013

maximin $\mathrm{H} 5$ to reduce the viability of cancer cells involves the adoption of $\alpha$-helical structure. The levels of this secondary structure are comparable to those mediating the antibacterial activity of native maximin H5 [32] and it is well established that the majority of HDPs adopt $\alpha$-helical structure to facilitate their anticancer and antimicrobial activities [7].

The ability of most HDPs to kill cancer cells is mediated by interactions with the plasma membrane of these cells, which, in some cases, can involve non-membranolytic mechanisms and intracellular sites of action [7,8]. For example, Cn-AMP2 from Cocos nucifera kills human glioblastoma cells via membrane translocation and attack on internal cellular components that lead to the induction of anti-proliferative mechanisms [21]. However, in most cases, the interaction of HDPs with the plasma membrane of cancer cells leads directly to permeabilization of this membrane and cell death via necrosis, and / or disruption of the mitochondrial membrane, resulting in cell death through apoptosis $[8,37,38]$. To investigate the ability of native maximin $\mathrm{H} 5$ to interact with the plasma membrane of cancer cells, MH5N was assayed for the ability to partition into monolayers formed from either DMPC or DMPS, and to release dye from vesicles also formed from these lipids. In the case of DMPC, MH5N showed high levels of monolayer penetration ( $\Pi=8.6 \mathrm{mN} \mathrm{m}^{-1}$, Table 1 , Figure $\left.3 \mathrm{~A}\right)$, and vesicle lysis (55\%, Table 1), indicating a strong hydrophobic contribution to the membrane interactions of the peptide. MH5N also showed high levels of interaction with similar lipid systems formed from DMPS, strongly penetrating monolayers $\left(\Pi=11.3 \mathrm{mN} \mathrm{m}{ }^{-1}\right.$, Table 1 , Figure $3 \mathrm{~A}$ ) and lysing vesicles (73.1\%, Table 1), indicating a strong electrostatic contribution to the membrane interactions of the peptide. In combination, these data suggest that the $\alpha$ helical structure adopted by the peptide in the presence of membranes is strongly amphiphilic. The adoption of high levels of amphiphilic structure is consistent with membranolytic ability and known to be a major driver in the anticancer and antimicrobial activity of many HDPs [7,39]. The possession of this $\alpha$-helical structure by native maximin H5 would allow its polar 
Dennison SR, Harris F and Phoenix DA (2017) Maximin H5 is an anticancer peptide, Biochimie accepted 27/02/2017. http://dx.doi.org/10.1016/j.biochi.2017.02.013

regions to target and interact with the lipid head group region of the membrane whilst its apolar regions would be able to concomitantly partition into the hydrophobic bilayer core. Consistent with these observations, MH5N induced maximal surface pressure changes of $\Pi=10.5 \mathrm{mN} \mathrm{m}^{-}$ ${ }^{1}$ in monolayer mimics of cancer cell membranes (Figure 3C), which is indicative of disruption of the acyl chain region [40]. The use of a dye release assay showed that the peptide induced high levels of lysis in vesicle mimics of cancer cell membranes (65.6\%, Table 1). In combination, these results clearly suggest that native maximin $\mathrm{H} 5$ possesses high levels of membranolytic activity, which facilitate the ability of the peptide to reduce the viability of T98G cells. These data would appear to discount the possibility that PE, which is present in the outer membrane leaflet of cancer cells [41,42], is able to inactivate the peptide via binding mechanisms similar to those described in the case of Escherichia coli (Figure 2) $[43,44]$. It has previously been demonstrated that native maximin $\mathrm{H} 5$ has a high affinity for PE and exhibits no propensity to partition into the plasma membrane of E. coli but remains anchored to their surface, primarily via a variety of peptide-lipid interactions and intra-peptide associations with PE head groups $[43,44]$. It seems likely that these effects are related to the levels of PE in membranes given that the molecule forms $\operatorname{circa} 80 \%$ of lipid in the E. coli inner membrane [45] but less than 30\% of plasma membrane lipid in the glioblastoma cells used here [36].

The monolayer and lysis data presented here (Table 1, Figure 3A, Figure 3B) also show that MH5N interacts more strongly with DMPS model membranes than those formed from DMPC, which correlates with the levels of $\alpha$-helical structure adopted by the peptide in the presence of these lipids. CD analysis showed that the levels of $\alpha$-helicity adopted by MH5N was $45 \%$ in the presence of vesicles formed from DMPC and rose to $60.75 \%$ in the case of those formed from DMPS (Table 1, Figure 2A). These results clearly suggest that the peptide has a preference for anionic lipid in its membrane interactions, which was confirmed using mixed DMPC / DMPS monolayers (lipid ratios varying from 100:1 to 10:1). These studies 
Dennison SR, Harris F and Phoenix DA (2017) Maximin H5 is an anticancer peptide, Biochimie accepted 27/02/2017. http://dx.doi.org/10.1016/j.biochi.2017.02.013

showed that the maximal surface pressure changes induced in these monolayers by the peptide correlated strongly with levels of DMPS $\left(\mathrm{R}^{2}>0.98\right.$, Figure 3C). In combination, these data suggest that anionic lipid promotes the membranolytic ability of native maximin $\mathrm{H} 5$ and similar results have been reported has been reported for the amphibian peptide, aurein 1.2, which has been shown to lyse membranes of the T98G cancer cells studied here [36]. A requirement for anionic lipid would also seem to help explain the fact that native maximin H5 low efficacy against non-cancerous SVGp12 cells (Figure 1) whose membranes are electrically neutral overall [36].

The preference shown by MH5 for anionic lipid data would also seem to support the view that, although anionic, the native peptide effectively functions as a cationic AMP. Studies on the antibacterial action of native maximin $\mathrm{H} 5$ suggested that the ability of the peptide to target and interact with bacterial membranes was mediated by the amidated residues at its two termini $[32,33]$. To investigate this possibility for the anticancer action of the peptide, the above work was repeated using a deaminated isoform of maximin H5, MH5C, which exhibited lower levels of $\alpha$-helical structure in the presence of cancer membrane mimics (44.8\%, Table 1 , Figure 2B) as well as decreased levels of interaction with DMPC $\left(\Pi=7.8 \mathrm{mN} \mathrm{m}^{-1}\right.$, Table 1 , Figure 3B) and DMPS monolayers ( $\Pi=10.2 \mathrm{mN} \mathrm{m}^{-1}$, Table 1, Figure 3B). In combination, these data suggest that the C-terminal amide of native maximin $\mathrm{H} 5$ helps maintain the levels of amphiphilicity possessed by this architecture that are required for the optimal lysis of cancer cell membranes. Indeed, it is well established that the propensity of AMPs to form $\alpha$-helical structure is strongly favoured by the presence of C-terminal amide groups, which provide an additional hydrogen bond for $\alpha$-helix stabilisation [46,47]. Consistent with a loss of membrane interactive $\alpha$-helical structure, MH5C showed a reduced ability to penetrate monolayer mimics of cancer cell membranes ( $\Pi=8.1 \mathrm{mN} \mathrm{m}^{-1}$, Table 1 , Figure 3B) and induce the lysis of vesicle mimics of these membranes (56.6\%, Table 1$)$. Clearly, these data also suggest that loss of the 
Dennison SR, Harris F and Phoenix DA (2017) Maximin H5 is an anticancer peptide, Biochimie accepted 27/02/2017. http://dx.doi.org/10.1016/j.biochi.2017.02.013

C-terminal amide possessed by MH5N reduces the ability of the peptide to promote its lysis of cancer cell membranes through targeting and interaction with anionic lipid components of these membranes. Confirming his suggestion, it was found that the maximal surface pressure changes induced in mixed DMPC/ DMPS monolayers by MH5C were circa $2.5 \mathrm{mN} \mathrm{m}^{-1}$ lower than those induced by MH5N at corresponding lipid compositions but still correlated strongly with levels of DMPS ( $\mathrm{R}^{2}>0.98$, Figure $\left.3 \mathrm{C}\right)$. In combination, these data clearly suggest that the Cterminal amide possessed by native maximin $\mathrm{H} 5$ plays a key role in optimizing the ability of the peptide to kill cancer cells and facilitates this ability through multiple functions. Indeed, the combined effects of C-terminal deamination on the membrane interactive potential of MH5N could help explain the kinetics of insertion into monolayers of DMPC and DMPS observed for MH5C (Figure 3). As can be seen from Figure 3A, insertion into these monolayers to achieve maximal surface pressure changes took MH5N less than a second whereas Figure 3B shows that MH5C took of the order of 450 seconds. These data clearly suggest the Cterminal amide of native maximin $\mathrm{H} 5$ is able to enhance not only enhance the depth of insertion shown by the peptide into cancer cell membranes but also its rate of insertion into these membranes.

\subsection{Conclusion}

In summary, here we have reported what appears to the first major example of anionic amphibian HDPs with anticancer activity, which involves membranolytic mechanisms that are promoted by anionic lipid and require both of the peptide's terminal amide groups for optimal action. The peptide showed specificity for cancer cells over non-cancerous cells and in combination, these results reinforce the view that the anticancer action of HDPs is dependent on the properties of both these peptides and the membranes of target cells [7]. The data 
Dennison SR, Harris F and Phoenix DA (2017) Maximin H5 is an anticancer peptide, Biochimie accepted 27/02/2017. http://dx.doi.org/10.1016/j.biochi.2017.02.013

presented here also shows that the anticancer activity of native maximin $\mathrm{H} 5$ exhibits a number of structure / function relationships that are shared by the antibacterial action of the peptide [32]. This observation supports the view that the ability of HDPs to kill cancer and microbial cells is generally promoted by common mechanisms and in particular that these peptides target these cells via the negative surface charge carried by their membranes [48,49]. A number of mechanisms to describe the antibacterial and anticancer action of HDPs have been proposed, including the carpet, the toroidal pore, the barrel stave pore and the tilted peptide models, and clearly, based on the data presented here, no particular model could be definitively assigned to the anticancer action of maximin H5 [7,10,39,50-52]. However, it is interesting to note that the peptide appears to form tilted $\alpha$-helical structure, which is required to promote its membrane interactions [32,44], and previous studies have shown that C-terminal deamidation can reduce the anticancer efficacy of tilted HDPs [53]. Moreover, the possession of this structural motif could indicate the potential to use a recently described, novel mechanism of membrane disruption in which tilted HDPs target the outer leaflet of the bilayer. According to this mechanism, the insertion of tilted peptides into the membrane triggers a rapid and continuous thinning of the outer leaflet; this action is accompanied by the formation of pores in the leaflet, which coalesce and cause local membrane rupture, leading to cell death [54]. As a final comment, it has recently been opined that anionic HDPs have the potential for a number of medical and biotechnological applications but appear to receive relatively little research attention in the literature $[17,18,55]$. Given the data presented here, it would seem that these peptides may represent an untapped potential source of novel anticancer agents that is awaiting full exploitation and merits much greater investigation. 
Dennison SR, Harris F and Phoenix DA (2017) Maximin H5 is an anticancer peptide, Biochimie accepted 27/02/2017. http://dx.doi.org/10.1016/j.biochi.2017.02.013

\subsection{References}

[1] L.A. Torre, F. Bray, R.L. Siegel, J. Ferlay, J. Lortet-Tieulent, A. Jemal, Global Cancer Statistics, 2012, Ca-a Cancer J. Clin. 65 (2015) 87-108. doi:10.3322/caac.21262.

[2] J. Ferlay, H.R. Shin, F. Bray, D. Forman, C. Mathers, D.M. Parkin, Estimates of worldwide burden of cancer in 2008: GLOBOCAN 2008, Int J Cancer. 127 (2010) 2893-2917. doi:10.1002/ijc.25516.

[3] W.W. Ma, A.A. Adjei, Novel Agents on the Horizon for Cancer Therapy (vol 59, page 111, 2009), Ca-a Cancer J. Clin. 60 (2010) 62. doi:10.3322/саac.20057.

[4] M.T. Piccolo, C. Menale, S. Crispi, Combined Anticancer Therapies: An Overview of the Latest Applications, Anticancer. Agents Med. Chem. 15 (2015) 408-422. <Go to ISI>://WOS:000353913200001.

[5] E. Piktel, K. Niemirowicz, M. Watek, T. Wollny, P. Deptula, R. Bucki, Recent insights in nanotechnology-based drugs and formulations designed for effective anti-cancer therapy, J. Nanobiotechnology. 14 (2016) 23. doi:10.1186/s12951-016-0193-x.

[6] R. Ali, Z. Mirza, G.M.D. Ashraf, M.A. Kamal, S.A. Ansari, G.A. Damanhouri, A.M. Abuzenadah, A.G. Chaudhary, I.A. Sheikh, New Anticancer Agents: Recent Developments in Tumor Therapy, Anticancer Res. 32 (2012) 2999-3005. <Go to ISI>://WOS:000306254300070.

[7] F. Harris, S.R. Dennison, J. Singh, D.A. Phoenix, On the selectivity and efficacy of defense peptides with respect to cancer cells, Med. Res. Rev. 33 (2013) 190-234. doi:10.1002/med.20252.

[8] D. Gaspar, A.S. Veiga, M.R.B. Castanho, From antimicrobial to anticancer peptides. A review, Front. Microbiol. 4 (2013). doi:10.3389/fmicb.2013.00294.

[9] K.C.L. Mulder, L.A. Lima, V.J. Miranda, S.C. Dias, O.L. Franco, Current scenario of peptide-based drugs: the key roles of cationic antitumor and antiviral peptides, Front. Microbiol. 4 (2013). doi:10.3389/fmicb.2013.00321.

[10] G. Gabernet, A.T. Muller, J.A. Hiss, G. Schneider, Membranolytic anticancer peptides, Medchemcomm. 7 (2016) 2232-2245. doi:10.1039/C6MD00376A.

[11] A. Tyagi, A. Tuknait, P. Anand, S. Gupta, M. Sharma, D. Mathur, A. Joshi, S. Singh, A. Gautam, G.P.S. Raghava, CancerPPD: a database of anticancer peptides and proteins, Nucleic Acids Res. 43 (2015) D837-D843. doi:10.1093/nar/gku892.

[12] A.T.Y. Yeung, S.L. Gellatly, R.E.W. Hancock, Multifunctional cationic host defence peptides and their clinical applications, Cell. Mol. Life Sci. 68 (2011) 2161-2176. doi:10.1007/s00018-011-0710-x.

[13] A. Varadhachary, R. Barsky, F. Pericle, K. Petrak, Y. Wang, Lactoferrin in the treatment of malignant neoplasms and other hyperproliferative diseases, 2012. <Go to ISI>://BCI:BCI201200590494.

[14] H. Tsuda, T. Kozu, G. Iinuma, Y. Ohashi, Y. Saito, D. Saito, T. Akasu, D.B. Alexander, M. Futakuchi, K. Fukamachi, J. Xu, T. Kakizoe, M. Iigo, Cancer prevention by bovine lactoferrin: from animal studies to human trial, Biometals. 23 
Dennison SR, Harris F and Phoenix DA (2017) Maximin H5 is an anticancer peptide, Biochimie accepted 27/02/2017. http://dx.doi.org/10.1016/j.biochi.2017.02.013

(2010) 399-409. doi:10.1007/s10534-010-9331-3.

[15] C. Ghosh, J. Haldar, Membrane-Active Small Molecules: Designs Inspired by Antimicrobial Peptides, ChemMedChem. 10 (2015) 1606-1624. doi:10.1002/cmdc.201500299.

[16] B.E. Haug, K.A. Camilio, L.T. Eliassen, W. Stensen, J.S. Svendsen, K. Berg, B. Mortensen, G. Serin, J.-F. Mirjolet, F. Bichat, O. Rekdal, Discovery of a 9-mer Cationic Peptide (LTX-315) as a Potential First in Class Oncolytic Peptide, J. Med. Chem. 59 (2016) 2918-2927. doi:10.1021/acs.jmedchem.5b02025.

[17] F. Harris, S.R. Dennison, D.A. Phoenix, Anionic Antimicrobial Peptides from Eukaryotic Organisms, Curr. Protein Pept. Sci. 10 (2009) 585-606. <Go to ISI $>$ ://WOS:000271386100006.

[18] F. Harris, S.R. Dennison, D.A. Phoenix, Anionic Antimicrobial Peptides from Eukaryotic Organisms and their Mechanisms of Action, Curr. Chem. Biol. 5 (2011) 142-153. doi:http://dx.doi.org/10.2174/2212796811105020142.

[19] S. Prabhu, S.R. Dennison, B. Lea, T.J. Snape, I.D. Nicholl, I. Radecka, F. Harris, Anionic Antimicrobial and Anticancer Peptides from Plants, CRC. Crit. Rev. Plant Sci. 32 (2013) 303-320. doi:10.1080/07352689.2013.773238.

[20] F. Harris, S. Prabhu, S.R. Dennison, T.J. Snape, R. Lea, M. Mura, D.A. Phoenix, Anionic Host Defence Peptides from the Plant Kingdom: Their Anticancer Activity and Mechanisms of Action, Protein Pept Lett. 23 (2016) 676-687.

[21] S. Prabhu, S.R. Dennison, M. Mura, R.W. Lea, T.J. Snape, F. Harris, Cn-AMP2 from green coconut water is an anionic anticancer peptide, J. Pept. Sci. 20 (2014) 909-915. doi:10.1002/psc.2684.

[22] S. Troeira Henriques, Y.-H. Huang, S. Chaousis, C.K. Wang, D.J. Craik, Anticancer and Toxic Properties of Cyclotides are Dependent on Phosphatidylethanolamine Phospholipid Targeting, ChemBioChem. 15 (2014) 1956-1965. doi:10.1002/cbic.201402144.

[23] R. Liu, H. Liu, Y. Ma, J. Wu, H. Yang, H. Ye, R. Lai, There are Abundant Antimicrobial Peptides in Brains of Two Kinds of Bombina Toads, J. Proteome Res. 10 (2011) 1806-1815. doi:10.1021/pr101285n.

[24] R. Lai, H. Liu, W. Hui Lee, Y. Zhang, An anionic antimicrobial peptide from toad Bombina maxima, Biochem. Biophys. Res. Commun. 295 (2002) 796-799. doi:http://dx.doi.org/10.1016/S0006-291X(02)00762-3.

[25] S. Prabhu, Effects of novel compounds in an in vitro chemosensitivity system for glioma treatment, University of Central Lancashire, 2012.

[26] T.P. Dawson, R. V Iyer, R.W. Lea, P. Roberts, F. Harris, K. Ashton, A. Golash, C.H.G. Davis, The MTS vs. the ATP assay for in vitro chemosensitivity testing of primary glioma tumour culture, Neuropathol. Appl. Neurobiol. 36 (2010) 564-567. doi:10.1111/j.1365-2990.2010.01096.x.

[27] N.J. Greenfield, Using circular dichroism spectra to estimate protein secondary 
Dennison SR, Harris F and Phoenix DA (2017) Maximin H5 is an anticancer peptide, Biochimie accepted 27/02/2017. http://dx.doi.org/10.1016/j.biochi.2017.02.013

structure, Nat. Protoc. 6 (2006) 2876-2890.

[28] L. Whitmore, B.A. Wallace, DICHROWEB, an online server for protein secondary structure analyses from circular dichroism spectroscopic data, Nucleic Acids Res. 32 (2004) W668-73. doi:10.1093/nar/gkh37132/suppl_2/W668 [pii].

[29] L. Whitmore, B. Woollett, A.J. Miles, R.W. Janes, B.A. Wallace, The protein circular dichroism data bank, a Web-based site for access to circular dichroism spectroscopic data, Structure. 18 (2010) 1267-1269. doi:S0969-2126(10)00307-2 [pii]10.1016/j.str.2010.08.008.

[30] L. Whitmore, B.A. Wallace, Protein secondary structure analyses from circular dichroism spectroscopy: methods and reference databases, Biopolymers. 89 (2008) 392-400. doi:10.1002/bip.20853.

[31] A. Seeling, Local anesthetics and pressure: a comparison of dibucaine binding to lipid monolayers and bilayers, Biochim. Biophys. Acta. 899 (1987) 196-204.

[32] S. Dennison, L. Morton, F. Harris, D.A. Phoenix, Low pH enhances the action of maximin $\mathrm{H} 5$ against Staphylococcus aureus and helps mediate lysylated phosphatidylglycerol induced resistance., Biochemistry. (2016) In press.

[33] S.R. Dennison, M. Mura, F. Harris, L.H.G. Morton, A. Zvelindovsky, D.A. Phoenix, The role of C-terminal amidation in the membrane interactions of the anionic antimicrobial peptide, maximin H5, Biochim. Biophys. Acta-Biomembranes. 1848 (2015) 1111-1118. doi:10.1016/j.bbamem.2015.01.014.

[34] L.T. Nguyen, E.F. Haney, H.J. Vogel, The expanding scope of antimicrobial peptide structures and their modes of action, Trends Biotechnol. 29 (n.d.) 464-472. doi:10.1016/j.tibtech.2011.05.001.

[35] M. Buck, Trifluoroethanol and colleagues: cosolvents come of age. Recent studies with peptides and proteins, Q Rev Biophys. 31 (1998) 297-355.

[36] S.R. Dennison, F. Harris, D.A. Phoenix, The interactions of aurein 1.2 with cancer cell membranes, Biophys. Chem. 127 (2007) 78-83.

doi:http://dx.doi.org/10.1016/j.bpc.2006.12.009.

[37] E.J. Paredes-Gamero, M.N.C. Martins, F.A.M. Cappabianco, J.S. Ide, A. Miranda, Characterization of dual effects induced by antimicrobial peptides: Regulated cell death or membrane disruption, Biochim. Biophys. Acta-General Subj. 1820 (2012) 1062-1072. doi:10.1016/j.bbagen.2012.02.015.

[38] X. Liu, Y. Li, Z. Li, X. Lan, P.H.M. Leung, J. Li, M. Yang, F. Ko, L. Qin, Mechanism of Anticancer Effects of Antimicrobial Peptides., J. Fiber Bioeng. Informatics. 8. (2015) 25-36.

[39] D.A. Phoenix, S.R. Dennison, F. Harris, Models for the Membrane Interactions of Antimicrobial Peptides, in: Antimicrob. Pept., Wiley-VCH Verlag GmbH \& Co. KGaA, 2013: pp. 145-180. doi:10.1002/9783527652853.ch5.

[40] S.R. Dennison, F. Harris, D.A. Phoenix, Langmuir-Blodgett Approach to Investigate Antimicrobial Peptide-Membrane Interactions, in: A. Iglic, C. V Kulkarni (Eds.), Adv. 
Dennison SR, Harris F and Phoenix DA (2017) Maximin H5 is an anticancer peptide, Biochimie accepted 27/02/2017. http://dx.doi.org/10.1016/j.biochi.2017.02.013

Planar Lipid Bilayers Liposomes, Vol 20, 2014: pp. 83-110. doi:10.1016/b978-0-12418698-9.00003-4.

[41] P. Williamson, R.A. Schlegel, Back and forth: the regulation and function of transbilayer phospholipid movement in eukaryotic cells, Mol Membr Biol. 11 (1994) 199-216.

[42] A. Marconescu, P.E. Thorpe, Coincident exposure of phosphatidylethanolamine and anionic phospholipids on the surface of irradiated cells, Biochim Biophys Acta. 1778 (2008) 2217-2224. doi:10.1016/j.bbamem.2008.05.006.

[43] S.R. Dennison, F. Harris, M. Mura, L.H.G. Morton, A. Zvelindovsky, D.A. Phoenix, A Novel Form of Bacterial Resistance to the Action of Eukaryotic Host Defense Peptides, the Use of a Lipid Receptor, Biochemistry. 52 (2013) 6021-6029. doi:10.1021/bi400719j.

[44] D.A. Phoenix, F. Harris, M. Mura, S.R. Dennison, The increasing role of phosphatidylethanolamine as a lipid receptor in the action of host defence peptides, Prog Lipid Res. 59 (2015) 26-37. doi:10.1016/j.plipres.2015.02.003.

[45] K. Lohner, E.J. Prenner, Differential scanning calorimetry and X-ray diffraction studies of the specificity of the interaction of antimicrobial peptides with membranemimetic systems, Biochim. Biophys. Acta-Biomembranes. 1462 (1999) 141-156. doi:10.1016/s0005-2736(99)00204-7.

[46] S.R. Dennison, J. Wallace, F. Harris, D.A. Phoenix, Amphiphilic alpha-helical antimicrobial peptides and their structure/function relationships, Protein Pept. Lett. 12 (2005) 31-39. doi:10.2174/0929866053406084.

[47] S.H. White, W.C. Wimley, Membrane protein folding and stability: Physical principles, Annu. Rev. Biophys. Biomol. Struct. 28 (1999) 319-365. doi:10.1146/annurev.biophys.28.1.319.

[48] J.S. Mader, D.W. Hoskin, Cationic antimicrobial peptides as novel cytotoxic agents for cancer treatment, Expert Opin Investig Drugs. 15 (2006) 933-946.

http://www.ncbi.nlm.nih.gov/entrez/query.fcgi?cmd=Retrieve\&db=PubMed\&dopt=Cit ation\&list_uids=16859395.

[49] D.W. Hoskin, A. Ramamoorthy, Studies on anticancer activities of antimicrobial peptides, Biochim Biophys Acta. 1778 (2008) 357-375. http://www.ncbi.nlm.nih.gov/entrez/query.fcgi?cmd=Retrieve\&db=PubMed\&dopt=Cit ation\&list_uids=18078805.

[50] Y. Huang, Q. Feng, Q. Yan, X. Hao, Y. Chen, Alpha-Helical Cationic Anticancer Peptides: A Promising Candidate for Novel Anticancer Drugs, Mini-Reviews Med. Chem. 15 (2015) 73-81. <Go to ISI>://WOS:000350752300009.

[51] S.R. Dennison, F. Harris, T. Bhatt, J. Singh, D.A. Phoenix, A theoretical analysis of secondary structural characteristics of anticancer peptides, Mol. Cell. Biochem. 333 (2010) 129-135. doi:10.1007/s11010-009-0213-3.

[52] S.R. Dennison, F. Harris, D.A. Phoenix, Are oblique orientated alpha-helices used by antimicrobial peptides for membrane invasion?, Protein Pept. Lett. 12 (2005) 27-29. 
Dennison SR, Harris F and Phoenix DA (2017) Maximin H5 is an anticancer peptide, Biochimie accepted 27/02/2017. http://dx.doi.org/10.1016/j.biochi.2017.02.013

doi:10.2174/0929866053406039.

[53] S.R. Dennison, F. Harris, T. Bhatt, J. Singh, D.A. Phoenix, The effect of C-terminal amidation on the efficacy and selectivity of antimicrobial and anticancer peptides, Mol. Cell. Biochem. 332 (2009) 43-50. doi:10.1007/s11010-009-0172-8.

[54] A. Pyne, M.-P. Pfeil, I. Bennett, J. Ravi, P. Iavicoli, B. Lamarre, A. Roethke, S. Ray, H. Jiang, A. Bella, B. Reisinger, D. Yin, B. Little, J.C. Munoz-Garcia, E. Cerasoli, P.J. Judge, N. Faruqui, L. Calzolai, A. Henrion, G.J. Martyna, C.R.M. Grovenor, J. Crain, B.W. Hoogenboom, A. Watts, M.G. Ryadnov, Engineering monolayer poration for rapid exfoliation of microbial membranes, Chem. Sci. 8 (2017) 1105-1115. doi:10.1039/C6SC02925F.

[55] E. Malik, S.R. Dennison, F. Harris, D.A. Phoenix, Eukaryotic antimicrobial peptides with $\mathrm{pH}$ dependent mechanisms of action, Pharmaceuticals. In press (2016). 
Dennison SR, Harris F and Phoenix DA (2017) Maximin H5 is an anticancer peptide, Biochimie accepted 27/02/2017. http://dx.doi.org/10.1016/j.biochi.2017.02.013

\section{Author's contribution}

DAP, SRD and FH conceptualized the project. SRD did the experimental work. SRD, FH and DAP prepared the manuscript

\section{Conflict of interest}

The authors declare that there are no conflicts of interest. 
Dennison SR, Harris F and Phoenix DA (2017) Maximin H5 is an anticancer peptide, Biochimie accepted 27/02/2017. http://dx.doi.org/10.1016/j.biochi.2017.02.013

Table 1. Biophysical properties of membranolytic maximin H5 isoforms

\begin{tabular}{|c|c|c|c|c|c|c|}
\hline & \multicolumn{3}{|c|}{ Maximin H5 } & \multicolumn{3}{c|}{ Deaminated maximin H5 } \\
& helicity (\%) & $\mathbf{m}^{-1}$ ) & & helicity (\%) & m $^{-1}$ ) & \\
\hline PBS buffer & 9 & - & - & 6 & - & - \\
\hline TFE & 68 & - & - & 62 & - & - \\
\hline DMPC & 45.0 & 8.6 & 55.3 & 35.3 & 7.8 & 46.2 \\
\hline DMPS/DMPC & 57.3 & 10.5 & 65.7 & 44.8 & 8.1 & 56.6 \\
(10:1) & & & & & & \\
\hline DMPS & 60.75 & 11.3 & 73.1 & 50.6 & 10.2 & 63.5 \\
\hline
\end{tabular}

$\Pi$ indicates the maximal surface pressure changes in lipid monolayers by isoforms of maximin H5. 
Figure 1. The activity of maximin $\mathrm{H} 5$ against cancer cell lines

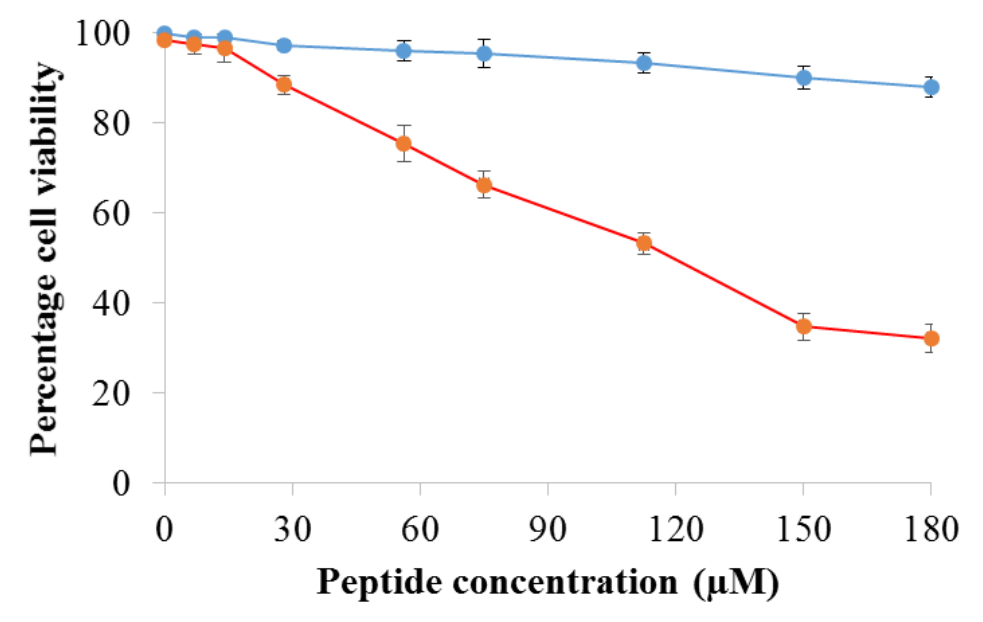

Figure 1 shows the effect of MH5N on the viability of cells of T98G, which is a glioblastoma cell line (red). Increasing concentrations of the peptide led to progressively larger reductions in the viability the cell lines until at a concentration $150 \mu \mathrm{M}$, these reductions were circa $70 \%$ as compared to controls. In contrast, at the same peptide concentration, MH5N induced reductions in the viability of the non-cancerous, human glial cell-line, SVGp12 (blue), of circa $10 \%$ as compared to controls. In all cases, experiments were performed in quadruplicate and the error bars represent the standard deviation. Non-linear regression analysis was used to yield the concentration of peptides that inhibited $50 \%$ of cancer cell growth (IC ${ }_{50}$ ) when compared to untreated controls. 
Figure 2. CD structural analysis of maximin H5 isoforms in lipid systems
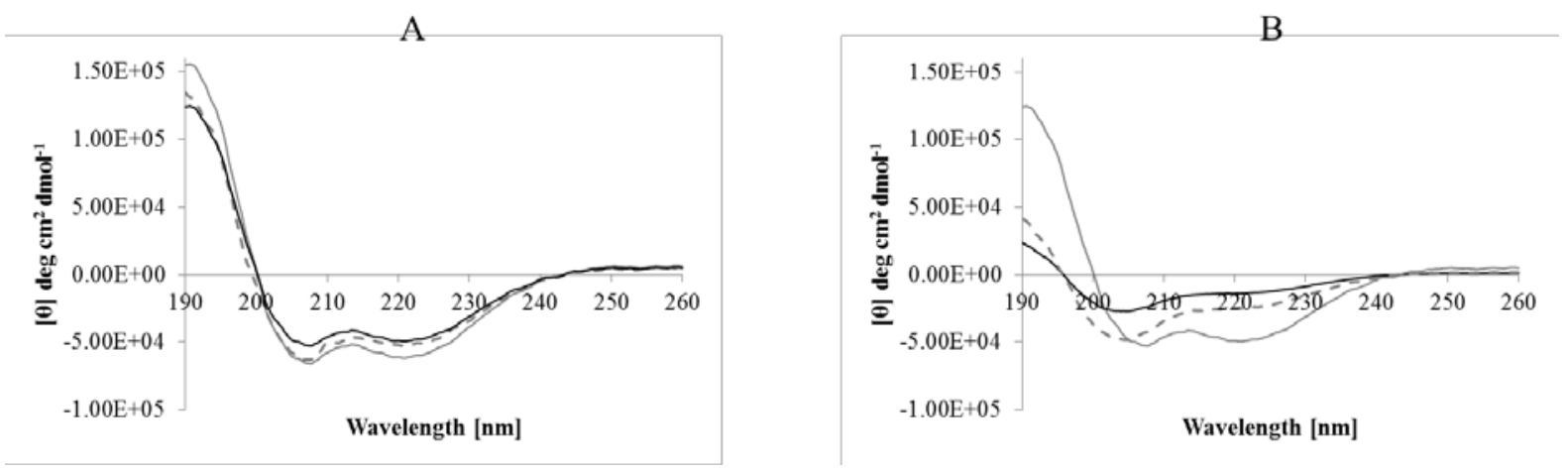

Figure 2 shows CD spectra for MH5N (Figure 2A) and MH5C (Figure 2B) in the presence of vesicles formed from DMPS (Dotted grey), DMPC (Solid grey) and DMPC / DMPS (molar ratio 10:1) (Solid black). In all cases, these spectra showed negative bands around 222 and 210 $\mathrm{nm}$, indicative of the presence of $\alpha$-helical structure. Analysis of these spectra showed that $\alpha$ helical contributions to the structure of MH5N ranged between $46.0 \%$ and $64.5 \%$ with the levels of this $\alpha$-helicity rising as the DMPS content of membranes increased (Table 1 ). Corresponding analysis of MH5C (Figure 2B) showed that $\alpha$-helical contributions to the structure of this peptide ranged between $35.7 \%$ and $51.4 \%$ and showed a similar correlation with DMPS membrane content (Table 1). For both peptides, the remaining structural contributions to their molecular architecture came from random coil and $\beta$-type structures (Figures 2A and 2B). A lipid composition of DMPC / DMPS (molar ratio 10:1) was taken to represent cancer cell membranes as previously described $[21,36]$ and in the presence of these membranes, MH5N and MH5C exhibited 57.5\% and 45.9\% $\alpha$-helicity respectively (Table 1). 
Figure 3. The interaction of maximin $\mathrm{H} 5$ isoforms with lipid monolayers
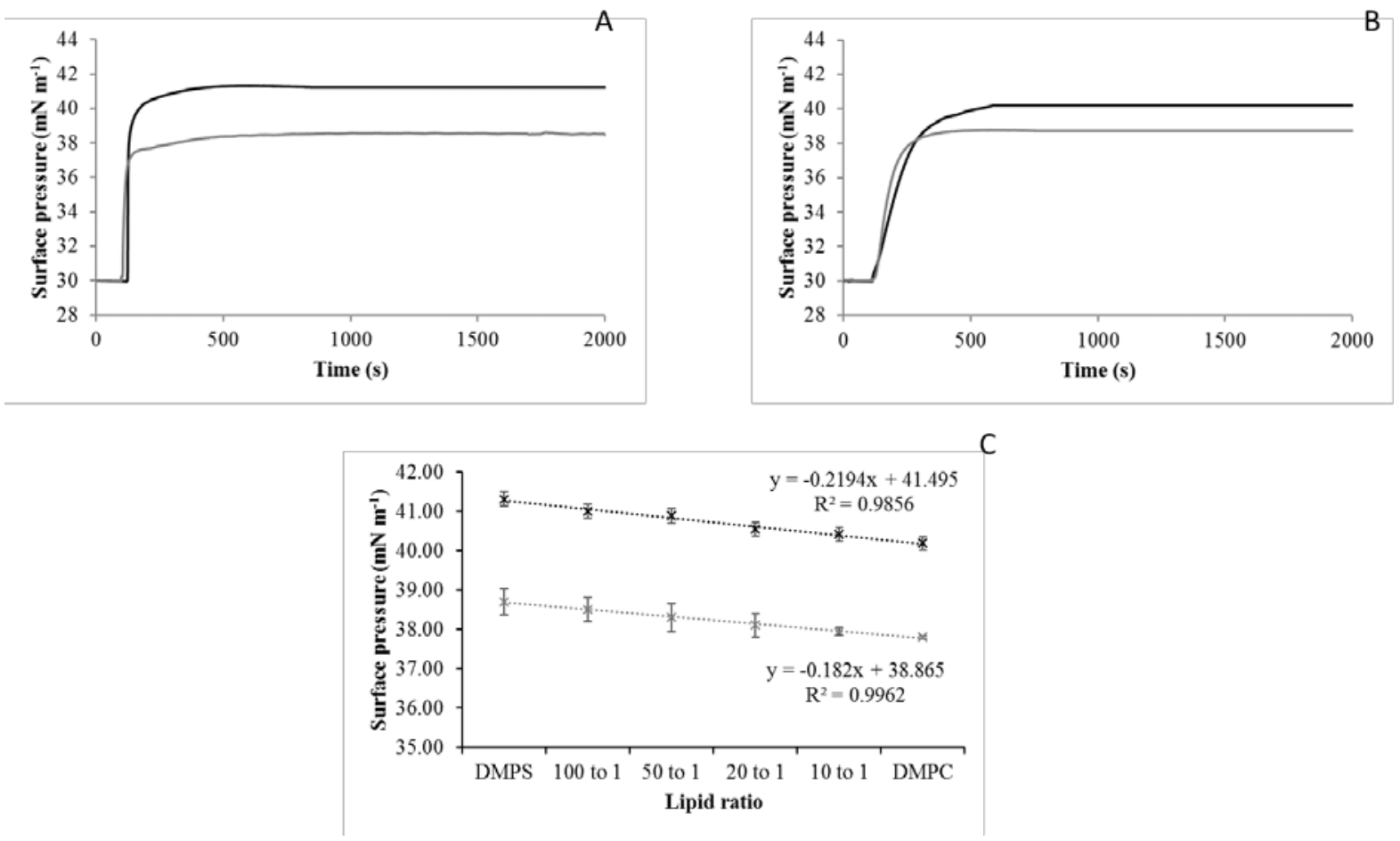

Figure 3A shows the interaction of MH5N with monolayers formed from DMPS (black) and DMPC (grey), which induced maximal surface pressure changes of $\Pi=11.3$ and $8.6 \mathrm{mN} \mathrm{m}^{-1}$ respectively. Figure 3B shows the corresponding interactions of $\mathrm{MH} 5 \mathrm{C}$ with monolayers formed from DMPS (black) and DMPC (grey), which induced maximal surface pressure changes of $\Pi=10.2 \mathrm{mN} \mathrm{m}^{-1}$ and $7.8 \mathrm{mN} \mathrm{m}^{-1}$ respectively (Table 1 ). Figure 3C show that the maximal surface pressure changes induced in membranes by both peptides correlated strongly with levels of DMPS in these membranes $\left(\mathrm{R}^{2}>0.98\right)$. Lipid compositions of DMPC / DMPS (molar ratio 10:1) were taken to represent cancer cell membranes as previously described $[21,36]$ and for these monolayers, MH5N and MH5C induced maximal surface pressure changes of $\Pi=10.5 \mathrm{mN} \mathrm{m}^{-1}$ and $8.1 \mathrm{mN} \mathrm{m}^{-1}$ respectively (Table 1 ). Surface pressure changes were determined relative to a surface pressure of $30 \mathrm{mN} \mathrm{m}^{-1}$, which is generally taken as that of naturally occurring biological membranes [31]. These experiments were performed in quadruplicate and the error bars represent the standard deviation. 
Dennison SR, Harris F and Phoenix DA (2017) Maximin H5 is an anticancer peptide, Biochimie accepted 27/02/2017. http://dx.doi.org/10.1016/j.biochi.2017.02.013 